\title{
Dinâmica Temporal da Clorose Variegada dos Citros em Três Regiões do Estado de São Paulo
}

\author{
Francisco F. Laranjeira ${ }^{1}$, Armando Bergamin Filho² ${ }^{2}$ Lilian Amorim² $^{2}$ Richard Berger $^{3}$ \\ \& Tim R. Gottwald ${ }^{4}$ \\ ${ }^{1}$ Embrapa Mandioca e Fruticultura, Cruz das Almas, BA, Brasil, Cx. Postal 007, CEP 44380-000, Fax: (75) 621-2149, \\ e-mail: chico@ cnpmf.embrapa.br; ${ }^{2}$ Departamento de Fitopatologia, ESALQ/USP, Piracicaba, SP; ${ }^{3}$ Universidade da Flórida, \\ Gainesville, Flórida, EUA; ${ }^{4}$ USDA-ARS, Fort Pierce, Flórida, EUA
}

(Aceito para publicação em 12/05/2003)

Autor para correspondência: Francisco F. Laranjeira

LARANJEIRA, F.F., BERGAMIN FILHO, A., AMORIM, L., BERGER, R. \& GOTTWALD, T.R. Dinâmica temporal da clorose variegada dos citros em três regiões do Estado de São Paulo. Fitopatologia Brasileira 28:481-488. 2003.

\section{RESUMO}

Este trabalho objetivou esclarecer se o progresso da Clorose Variegada dos Citros (CVC) diferia entre três regiões de São Paulo, distintas quanto à incidência da CVC em citrus (Citrus spp.). Foram avaliadas três áreas, Noroeste, Centro e Sul de São Paulo, durante dois anos, em avaliações quinzenais, quando eram mapeadas as plantas sintomáticas. Tentou-se o ajuste de nove modelos ao progresso da doença, além do ajuste de três modelos a segmentos das curvas originais. Foram estimadas também as diferenciais e as diferenciais secundárias de cada curva de progresso. Apenas quando as curvas foram divididas é que foram obtidos bons ajustes aos modelos de progresso. A diferencial (velocidade da doença) e diferencial secundária (aceleração do aparecimento de novas plantas doentes) apresentaram diversos picos ao longo do tempo. Esses picos ocorreram em meses de Primavera e Verão. Levanta-se aqui a hipótese de que os picos de diferencial - incomuns na quantidade encontrada - estejam relacionados a determinados picos de emissão de brotações, já que as novas brotações são o local preferido de alimentação dos vetores de Xylella fastidiosa.

Palavras-chave adicionais: CVC, Xylella fastidiosa, epidemiologia, diferencial.

\section{ABSTRACT}

Temporal dinamyes of Citrus Variegated Chlorosis in three Regions of São Paulo, Brazil

This study aimed to discover if the incidence differences between three regions in the State of São Paulo, Brazil could be related to different dynamics of Citrus Variegated Chlorosis (CVC) progress. Three areas of the State (Northwest, Center and South) were evaluated by visual assessments performed two times a month for two years. For each evaluation all plants were inspected and designated as diseased or healthy. Nine models were fit to each CVC progress curve, and three were fit to segments of original curves. Also, first and second derivatives were estimated for each curve. A good fit was obtained for segments of original curves. First and second derivatives showed many peaks over time. Most of those peaks occurred during the spring and summer months. Our hypothesis is that derivative peaks are related to flush emission peaks, considering that new sprouts are the preferred feed sites of Xylella fastidiosa vectors.

\section{INTRODUÇÃo}

A Clorose Variegada dos Citros (CVC) foi constatada pela primeira vez em 1987 (Rossetti et al., 1990) em plantas cítricas (Citrus spp.), no município de Colina-SP, e rapidamente tornou-se o mais importante problema fitossanitário da citricultura brasileira, com perdas que, segundo estimativas, já superaram os 650 milhões de reais (Prejuízos, 2001). Desde então, muito se fez para identificar e caracterizar a causa do problema, premissa indispensável, mas insuficiente, para chegar a um controle racional e econômico da doença. Assim, apenas três anos após sua constatação, associou-se a expressão dos sintomas de CVC à presença constante de Xylella fastidiosa Wells et al no xilema das plantas atacadas (Rossetti et al., 1990); em seguida, comprovou-se a patogenicidade da bactéria, completando-se os postulados de Koch (Chang et $a l ., 1993)$. A identificação de cigarrinhas vetoras do patógeno foi o próximo passo a ser elucidado (Roberto et al., 1996), abrindo perspectivas para uma melhor compreensão da dinâmica de progresso da doença. Durante todo esse período, ferramentas moleculares específicas para o patossistema Xylella-citros foram sendo desenvolvidas, o que permitiu, além de melhor compreensão do problema nos citros, a identificação da mesma estirpe de X. fastidiosa em cafeeiro (Coffea arabica L.) (Paradela Filho et al., 1997).

Contrastando com o rápido progresso da pesquisa na identificação e na caracterização molecular de X. fastidiosa como agente causal da CVC, a pesquisa epidemiológica tem recebido pouca atenção. Os poucos trabalhos epidemiológicos feitos até o momento (Palazzo \& Carvalho, 1992; Gottwald et al., 1993; Laranjeira, 1997; Nunes, 1999; Martins et al., 2000; Pereira, 2000) revelaram alguns aspectos relevantes como principais fontes de inóculo, não-influência de vento ou passagem de máquina na disseminação, épocas de maior 
aparecimento de plantas doentes e dinâmica espacial-temporal da doença na região Norte de São Paulo.

Por outro lado, a diferença na incidência da CVC entre as distintas regiões do Estado de São Paulo ainda não encontra explicação satisfatória. Em levantamentos feitos entre 1996 e 1999, Ayres (2000) mostrou que há um gradiente de incidência da doença entre as regiões citrícolas de São Paulo: Norte > Noroeste > Centro > Sul. O autor também não apresenta explicação, mas hipotetiza em relação a inóculo inicial, diferentes estirpes do agente causal e aspectos climáticos. Pereira (2000) e Wendland (2000), trabalhando respectivamente com flutuação populacional de cigarrinhas e estirpes da bactéria, mostraram diferenças entre as regiões, mas não puderam apontar esses aspectos como explicações definitivas. O objetivo desse trabalho foi caracterizar a dinâmica temporal da CVC em talhões de três regiões do Estado de São Paulo (Noroeste, Centro e Sul).

\section{MATERIAL E MÉTODOS}

Áreas

Foram selecionados talhões homogêneos de laranja doce (Citrus sinensis Osbeck), variedade Pêra, enxertada em limão Cravo (Citrus limonia Osbeck), representativos das três principais áreas citrícolas do Estado de São Paulo. Todas as áreas estavam com cerca de quatro anos de idade quando do início dos trabalhos.

(i) Região Noroeste - Estância Lilian, localizada no município de Neves Paulista; a área selecionada conta com 684 plantas, dispostas em 18 linhas de plantio, pertencentes a pomar com cerca de 3.000 plantas.

(ii) Região Central - Sítio Carioca, localizado no município de Gavião Peixoto; a área selecionada conta com 972 plantas, dispostas em 18 linhas de plantio, pertencentes a pomar com cerca de 5.000 plantas.

(iii) Região Sul - Sítio Taquaral, localizado no município de Santa Rita do Passa Quatro; a área selecionada conta com 1080 plantas, dispostas em 18 linhas de plantio, pertencentes a pomar com cerca de 8.000 plantas.

\section{Avaliações}

As avaliações foram feitas quinzenalmente. Todas as plantas de cada talhão eram observadas em busca de sintomas típicos da CVC, sejam em folhas ou em frutos. O estado fitopatológico era anotado, obtendo-se a proporção acumulada de plantas sintomáticas de cada talhão em cada data de avaliação.

\section{Ajuste de modelos às curvas de progresso}

Inicialmente foram escolhidos nove modelos (Campbell \& Madden, 1990; Hau et al., 1993) a serem ajustados aos dados. Os quatro primeiros são generalizações de modelos amplamente utilizados para análise de epidemias em fitopatologia (Bergamin Filho \& Amorim, 1996): Gompertz com quatro ou cinco parâmetros; Logístico com quatro ou cinco parâmetros; Monomolecular; Gompertz; Logístico; LogLogístico e Richards. As curvas foram também divididas em segmentos conforme suas diferenciais e cada segmento foi reanalisado por ajuste dos modelos Logístico, Monomolecular e Gompertz.

Os dados foram analisados por meio de regressão nãolinear com o software STATISTICA 5.0. A regressão não-linear foi feita através do método Quasi-Newton, que estima assintoticamente as diferenciais de segunda ordem (parciais) da função de perda $\left(\right.$ perda $\left.=(\text { observado }- \text { previsto })^{2}\right)$ e as usa para determinar o movimento dos parâmetros de iteração a iteração. A escolha do melhor modelo foi feita com base no coeficiente de determinação entre valores observados e valores previstos; na existência ou não de padrões no gráfico de resíduos versus valores previstos e nos valores do quadrado médio do resíduo (Campbell \& Madden, 1990).

\section{RESULTADOS E DISCUSSÃO}

\section{Avaliações}

Em nenhum dos talhões estudados houve tentativa de controle da doença por utilização de poda ou arranquio de plantas. Na região Sul, algumas plantas haviam sido substituídas por mudas, mas tal fato ocorreu antes do início dos trabalhos. Dessa maneira, não foi necessário o estudo das áreas a partir de modelos específicos para doenças com arranquio e replanta, como o sugerido por Chan \& Jeger (1994). Em nenhum momento houve necessidade de testes específicos para distinguir os sintomas típicos de outros como deficiências nutricionais ou cloroses causadas pela alimentação de cochonilhas.

\section{Progresso da doença}

As curvas de progresso da CVC para todas as áreas apresentaram padrão incomum para doenças de causa biótica (Figura 1). A priori, não foi possível distinguir uma forma típica para a curva de progresso. Os dados foram ajustados a nove modelos comumente usados em análise epidemiológica (Campbell \& Madden, 1990) e, na maioria dos casos, foram obtidos bons coeficientes de determinação. No entanto, todos os modelos ajustados aos dados das regiões Noroeste e Centro apresentaram, em maior ou menor grau, padrão de resíduos. Esses padrões foram observados para toda a epidemia ou limitados à sua parte final. Na região Sul, apenas os modelos Duplos Sigmóides Logístico e Gompertz de cinco parâmetros e o modelo Log-Logístico não apresentaram padrão no gráfico de resíduos.

As curvas de progresso da CVC não seguiram um padrão comum a todas as regiões. A única curva em que foi possível o ajuste de um modelo matemático previamente conhecido foi a obtida na região Sul. Esse modelo, que apresenta como característica principal uma alternância entre períodos de progresso rápido (sigmóides) e lento é denominado sigmóide duplo (Bergamin Filho \& Amorim, 1996), e também pode ser observado para outros sistemas (Hau et al., 1993). Para o patossistema em questão, curvas de padrão duplo-sigmóide já haviam sido observadas (Laranjeira, 1997). Esse autor estudou o progresso da doença em 11 áreas, de três variedades de 
Dinâmica temporal da clorose variegada dos citros em três regiões ...

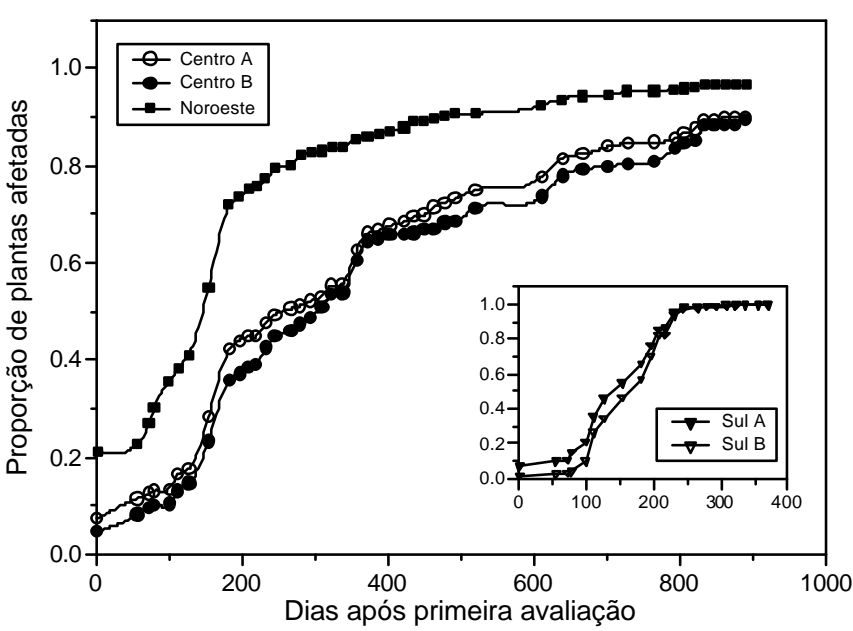

FIG. 1 - Curvas originais de progresso da Clorose Variegada dos Citros (CVC) para os talhões das regiões Noroeste, Centro e Sul.

laranja doce, no norte do Estado de São Paulo e, em todos os casos, encontrou o padrão duplo-sigmóide. Dentre os diversos modelos testados, escolheu o logístico generalizado de cinco parâmetros, um dos que bem se ajustaram aos dados da região Sul, aqui analisados. No entanto, segundo Laranjeira (1997), as fases de progresso lento e rápido estavam bem delimitadas para seus dados: aumento intenso da incidência na Primavera e Verão e quase paralização do progresso entre o Outono e o Inverno. Tal fato não ocorreu neste trabalho com a curva da região Sul: as duas fases sigmóides são bem caracterizadas, mas o período de progresso lento é quase imperceptível (Figura 1). De maneira geral, o progresso da CVC relatado por Laranjeira (1997) foi mais lento que o aqui observado para a região Sul. Para os talhões comparáveis (mesma idade, copa e portaenxerto), os níveis máximos de incidência foram alcançados após 20 meses de início da epidemia. No presente caso, chegouse a esses níveis após apenas cerca de 12 meses. Nas regiões Noroeste e Centro, embora o padrão tenha sido diferente (Figura 1), a incidência máxima foi alcançada em períodos compatíveis com os obtidos por Laranjeira (1997).

O progresso mais intenso da doença na região Sul não era esperado. Todos os levantamentos realizados até agora (Ayres, 2000; Fundecitrus, 2002) apontam a região Sul citrícola de São Paulo como a menos afetada pela CVC, seja em termos de incidência ou de severidade. Os dados de incidência obtidos para o talhão avaliado também são discordantes dos obtidos por Laranjeira em Cordeirópolis, também região Sul (dados não publicados). Os resultados são também diferentes dos relatados por Gottwald et al. (1993) e Nunes (1999). Os primeiros, em avaliações anuais, acharam que o progresso da CVC seguia o modelo simples de Gompertz. A diferença de resultados pode ter origem num padrão realmente diferente no progresso da doença, ou pode ser atribuído em parte ao intervalo de tempo entre avaliações. Nunes (1999), por sua vez, acompanhou talhões similares aos avaliados por Laranjeira (1997), e fez avaliações bimestrais; chegou a resultados similares aos de Gottwald et al. (1993), mas não tentou o ajuste de modelos sigmóides-duplos para seus dados.

Enquanto Gottwald et al. (1993) só fizeram levantamentos uma vez ao ano e Laranjeira (1997) optou por avaliações bimestrais, aqui foram realizadas mais de 20 avaliações anuais, tendo sido possível observar detalhes que aqueles autores não puderam detectar. Talvez por isso, os períodos de progresso lento relatados por Laranjeira (1997), devessem ter sido confirmados e melhor caracterizados, fato que não ocorreu. Um outro aspecto diz respeito à época de progresso lento: Laranjeira (1997) apontou-a como sendo o período normalmente associado ao déficit hídrico em São Paulo, Outono/Inverno. Nessa época, para o talhão da região Sul, a curva de progresso já havia alcançado a assíntota.

Laranjeira (1997) chegou a discutir a possibilidade de que, com uma análise de informações em base anual, pudessem ser obtidos resultados similares aos de Gottwald et al. (1993). No entanto, quer os dados de Laranjeira (1997) quanto os aqui apresentados indicam - pelo menos para o talhão da região Sul - um progresso muito mais rápido do que o suposto por Gottwald et al. (1993). A explicação mais simples é a de que, desde aquela época - fins da década dos anos 80 e início da dos 90 - ampliaram-se as fontes de inóculo, a severidade da doença aumentou (Fundecitrus, 2002), supostamente aumentou também a quantidade de espécies vetoras e sua proporção de indivíduos infetivos, levando a um aumento na taxa de progresso da doença. Por outro lado, uma outra hipótese pode ser a de que a maior parte das plantas daquele talhão tenham vindo do viveiro já contaminadas com $X$. fastidiosa. Quando as condições ambientais foram - supostamente favoráveis, os sintomas manifestaram-se. Outras evidências dessa hipótese, relacionadas ao padrão espacial da doença foram abordadas por Laranjeira (2002).

Nas regiões Noroeste e Centro nenhum modelo que descreva o progresso de patologias vegetais pôde ser ajustado aos dados. Laranjeira (1997) discutiu a possibilidade de, para doenças poliéticas como parece ser o caso da CVC, serem observadas curvas de progresso não duplo, mas triplo ou quádruplo-sigmóides. Para essas curvas, novos modelos matemáticos teriam que ser desenvolvidos. No entanto, esse autor avaliou essa possibilidade considerando picos de diferencial bem definidos, tais quais os por ele observados.

Em função do ajuste pobre obtido para as curvas completas, optou-se por dividí-las em função dos picos de diferencial observados (Figura 2). Na maioria das vezes, para dar consistência de forma ou de número de pontos da curva, foi necessário que segmentos contíguos compartilhassem pelo menos uma avaliação. Como as proporções de plantas afetadas iniciais e finais de cada segmento variavam, optou-se por padronizá-los para permitir um ajuste mais consistente e uma melhor interpretação dos resultados. Assim, a maior proporção de plantas doentes de cada segmento foi considerada como 1,0, a menor, como zero, e a primeira avaliação de cada segmento foi considerada como tempo 0 . Os tempos e proporções foram então recalculados.

A epidemia na região Noroeste foi dividida em quatro. O primeiro segmento abrangeu da primeira avaliação até a sexta 
F.F. Laranjeira et al.
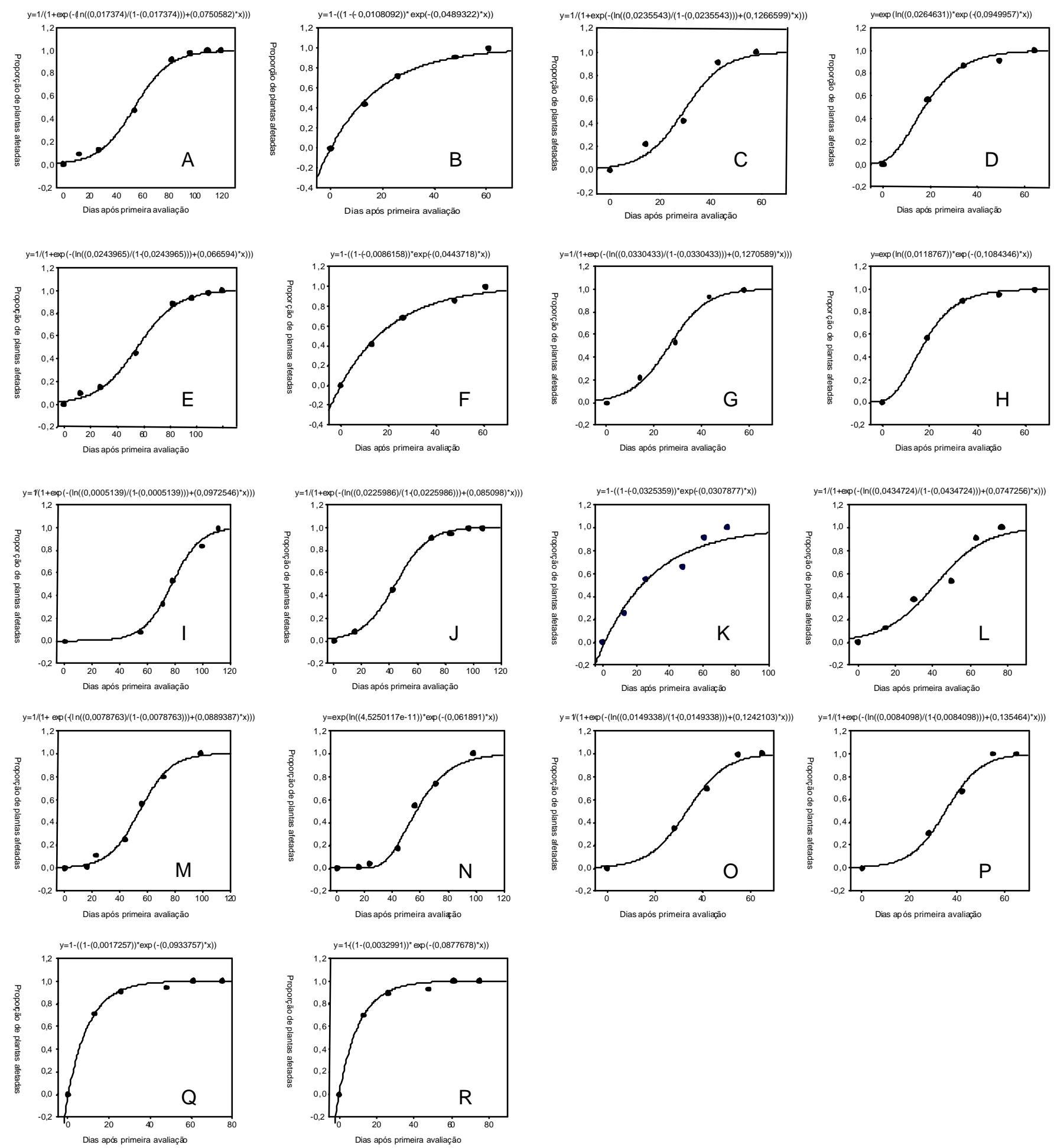

FIG. 2 - Curvas de progresso da Clorose Variegada dos Citros (CVC) estimadas (linha contínua), dados originais (círculos) e equações de ajuste do melhor modelo para cada segmento das curvas originais dos talhões das regiões Noreste (A a D), Centro A (E a H), Centro B (I a L), Sul A (M a O) e Sul B (P a R).

(111 dias após primeira avaliação - DAPA), o segundo, da sexta

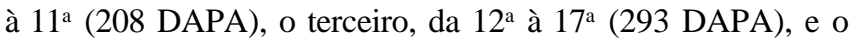
último segmento, da $22^{\mathrm{a}}$ à $27^{\mathrm{a}}$ avaliação (448 DAPA). Os talhões das regiões Centro e Sul foram divididos em dois cada, em razão de uma aparente diferença no número inicial de plantas doentes de cada sub-área. Para a região Centro, em ambas as sub-áreas (A e B), as curvas foram divididas em quatro segmentos: O primeiro segmento abrangeu da quinta avaliação 
Dinâmica temporal da clorose variegada dos citros em três regiões ...

até a $12^{\text {a }}$ (218 dias após primeira avaliação - DAPA), o segundo, da $12^{\mathrm{a}}$ à $16^{\mathrm{a}}$ (279 DAPA), o terceiro, da $16^{\mathrm{a}}$ à $20^{\mathrm{a}}$ (337 DAPA), e o último segmento, da 20a à $24^{\mathrm{a}}$ avaliação (401 DAPA). Para a região Sul, as curvas de ambas as sub-áreas (A e B) foram divididas em três segmentos, o primeiro indo da segunda à oitava avaliação (153 DAPA), o segundo, indo da oitava à 12a avaliação (218 DAPA), e o último segmento, abrangendo desde a $12^{\mathrm{a}}$ até a $17^{\mathrm{a}}$ avaliação (293 DAPA).

O modelo logístico foi o único a não apresentar padrões nos gráficos de resíduos em qualquer dos segmentos de curva analisados (Tabela 1). Apesar disso, não pode ser considerado o modelo que melhor explica a evolução da CVC em todos os segmentos. De fato, baseado não só na inexistência de padrão nos resíduos, mas também nos valores do coeficiente de determinação e do quadrado médio do resíduo, o modelo monomolecular foi o mais adequado para cinco segmentos e o Gompertz, para três (Tabela 1).

Na epidemiologia botânica é comum a simplificação de que, para os modelos sigmóides (logístico e Gompertz, por exemplo), sítios infetados servem como fonte de inóculo num mesmo ciclo. No caso da CVC essa simplificação é inválida. Plantas sintomáticas são fonte de inóculo para plantas sadias de uma mesma área (Laranjeira, 1997), mas, em função do longo período de incubação (Lopes et al, 1996), não seria possível a manifestação de sintomas em ciclo secundário no período de tempo que cada segmento das curvas abrangeu (entre 58 dias - Centro A_3 - e 119 dias - Centro A_1). Assim, é possível admitir que as curvas obtidas são possivelmente um reflexo da interação entre fenologia da planta, clima e manifestação de sintomas. Comportamentos sigmóides em fenômenos naturais são comuns; Laranjeira et al. (2000), por exemplo, trabalhando com sementes de frutos afetados pela CVC, mostraram que a germinação seguia o modelo logístico.

Por outro lado, apesar de ter sido considerado o modelo mais adequado em apenas $28 \%$ dos segmentos, a equação monomolecular se ajustou bem a outros dois segmentos de curva (Tabela 1). Destacando o aspecto biológico, em detrimento do matemático, esse seria o modelo mais congruente com o progresso da CVC naqueles segmentos de curva. Isto se dá precisamente em virtude da impossibilidade de ciclos secundários da doença em períodos curtos de tempo, como explicado anteriormente. $\mathrm{O}$ sentido biológico de tal modelo deriva do seguinte arrazoado: i) admite-se que a maior parte das infecções ocorra em ramos novos, em função da preferência alimentar dos vetores (Lopes, 1999); ii) embora possam ocorrer ao longo do ano, independentes da região, a maior parte das brotações novas são detectadas em picos, especialmente no final de inverno e início da Primavera no Estado de São Paulo (Laranjeira, 2002); iii) o período de incubação, para infecções via vetores, é de pelo menos seis meses, mas mais comumente um ano (Lopes et al., 1996; Laranjeira, 1997); iv) há evidências biológicas e probabilísticas de que as plantas cítricas são mais propensas à infecção entre a Primavera e o Verão (Pereira, 2000; Martins et al., 2000); v) o crescimento de uma dada população de vetores geralmente alcança sua taxa máxima na Primavera (Paiva et al, 1996; Garcia

TABELA 1 - Coeficiente de determinação $\left(\mathrm{R}^{2}\right)$, existência (+) ou não (-) de padrão no gráfico de resíduos e quadrado médio do resíduo (QMR x $10^{4}$ ) em função do ajuste de três modelos ao progresso da Clorose Variegada dos Citros (CVC) de segmentos de curvas em três regiões do Estado de São Paulo

\begin{tabular}{|c|c|c|c|c|c|c|c|c|c|}
\hline \multirow{3}{*}{ Segnuento } & \multicolumn{9}{|c|}{ Mivdèlo } \\
\hline & \multicolumn{3}{|c|}{ Momomalecular } & \multicolumn{3}{|c|}{ Ingifiticn } & \multicolumn{3}{|c|}{ Gomperts. } \\
\hline & $\mathbf{R}^{2}$ & $\begin{array}{l}\text { Padrato de } \\
\text { Ratyduxys }\end{array}$ & $\begin{array}{l}\text { QMR } \\
\text { X10 }\end{array}$ & $\mathbf{R}^{2}$ & $\begin{array}{l}\text { Padrato de } \\
\text { Resícluog }\end{array}$ & $\begin{array}{l}\text { QMK } \\
\text { X10 }\end{array}$ & $\mathbf{R}^{2}$ & $\begin{array}{l}\text { Padráto de } \\
\text { Resíluos }\end{array}$ & $\begin{array}{l}\text { QMK } \\
\mathbf{X} 10^{4}\end{array}$ \\
\hline Noroeste:" & 0,646 & + & 481 & 11,994 & - & 9 & 0,956 & - & 60 \\
\hline Vorose 2 & 0,922 & 1 & 132 & $(1,994)$ & - & 1,5 & 0,445 & - & lis 1 \\
\hline Noroese 3 & $0,959^{4 *}$ & - & 51 & 0,943 & & 69 & $0,96:$ & - & $\angle 9$ \\
\hline Noroeste' & $0,8 / 8$ & + & 168 & 10,960 & - & 54 & $0,95:$ & - & $6 \%$ \\
\hline Gentro A 1 & 0,896 & + & 183 & 11,996 & - & 7 & 0.984 & - & 28 \\
\hline Clinteo A 2 & 0,995 & - & 7 & 0,967 & - & 13 & 0.987 & - & 17 \\
\hline Centom A_3 & $0,86.5$ & 1 & 2014 & 0,974 & - & 39 & 0,952 & - & 73 \\
\hline Centim A_4 & 0,000 & - & 13 & 0,081 & - & 26 & 0,095 & - & 7 \\
\hline Centro $\mathrm{B}_{-}{ }_{-1}$ & 0,906 & 1 & 155 & 0,996 & - & 6 & 0,586 & & 24 \\
\hline concro B-2 & $(1,59) 1$ & - & 11 & 0,954 & - & 58 & 0,478 & - & 27 \\
\hline Cemulx I3 3 & $0,90 \%$ & 1 & 152 & 0,989 & - & 17 & 0,579 & - & 32 \\
\hline Centro 13 & 0,986 & - & 19 & 0,991 & - & 1.3 & 10,998 & - & 2 \\
\hline Sul $A_{-}{ }^{-}$ & 0,834 & 1 & 225 & 10,994 & - & 9 & 0,486 & - & 20 \\
\hline 3 sul $\Lambda^{-} 2$ & 0,867 & & 198 & 10,992 & - & 12 & 0,988 & & 18 \\
\hline Sul A 3 & 11,997 & - & 4 & 0,981 & - & 20 & 0,990 & - & 13 \\
\hline Sul R 1 & 0,801 & + & 277 & 0,988 & - & 16 & 0,984 & - & 16 \\
\hline Sul R_2 & $0,8.34$ & - & 259 & 0,992 & - & 13 & 0.986 & - & 22 \\
\hline Sul $\mathrm{T}^{-} 3$ & 0,995 & - & 6 & 0,977 & - & 29 & 0.985 & - & 19 \\
\hline
\end{tabular}

*Noroeste 1 (0 a 111 dias após primeira avaliação - DAPA); Noroeste 2 (111 a 208 DAPA); Noroeste 3 (218 a 293 DAPA); Noroeste 4 (371 a 448 DAPA). CentroA1 e B1 (99 a 218 DAPA); Centro A2 e B2 (218 a 279 DAPA); Centro A3 e B3 (279 a 337 DAPA); Centro A4 e B4 (337 a 401 DAPA). Sul A1 e B1 (55 a 153 DAPA); Sul A2 e B2 (153 a 218 DAPA); Sul A3 e B3 (218 a 293 DAPA).

**Células em negrito indicam modelo que melhor se ajustou aos dados para cada segmento de curva. 
et al., 1997).

Ora, a junção desses cinco fatos resulta numa restrição à interação eficiente entre vetores infetivos e hospedeiro suscetível - planta com brotações novas -, sob a égide do ambiente - que influencia a predisposição da planta às infecções. Ou seja, os contatos efetivos, base do modelo monomolecular (Bergamin Filho \& Amorim, 1996) são restritos a um curto período de tempo. Os contatos efetivos são função do inóculo disponível e da taxa de infecção (Bergamin Filho \& Amorim, 1996). No caso da CVC, o "inóculo disponível” pode ser representado pela população de vetores infetivos, e a taxa de infecção seria dada pela combinação de uma série de variáveis: disponibilidade de biomassa suscetível; proporção de infecções bem-sucedidas em razão de condições climáticas e infetividade dos vetores, por exemplo. Nesse contexto, a detecção de plantas sintomáticas refletiria a realização anterior daqueles contatos efetivos.

Não há ainda uma explicação biológica plausível para a forma sigmóide de alguns segmentos de curvas. Resta, portanto, à luz dos conhecimentos atuais, considerar o ajuste dos modelos logístico e/ou Gompertz como resultante de uma interação complexa de fenologia da planta e manifestação de sintomas, mas não associada a eventos de infecção.

\section{Diferenciais}

As diferenciais foram obtidas a partir das curvas originais, sem divisão dos talhões das regiões Centro e Sul. A análise das diferenciais do talhão da região Noroeste revela a existência de dois picos de maior intensidade (Figura 3a) aos 78 e 153 DAPA, seguidos de picos de menor intensidade aos 231, 421 e 610 DAPA. A intensidade do pico não se relacionou com cronologia, já que o pico ocorrido aos 153 DAPA foi o mais intenso. Os picos de maior intensidade - 78 e 153 DAPA correspondem, em datas, ao início de outubro de 1998 (Primavera) e meados de dezembro de 1998 (Primavera). Os picos de menor intensidade ocorreram no Verão de 1999, final de Inverno de 1999 e Verão de 2000.

O talhão da região Centro foi o que apresentou maior quantidade de picos de diferencial bem definidos, cinco ao todo (Figura 3b). Os picos mais intensos ocorreram aos $153 \mathrm{e}$ 356 DAPA, intercalados por um aos 231 DAPA, de menor intensidade. Aos 610 e 820 DAPA foram observados mais dois picos. Os cinco picos ocorreram, por ordem cronológica, em meados de dezembro de 1998 (Primavera), março de 1999 (Verão), julho de 1999 (Inverno), março de 2000 (Verão) e outubro de 2000 (Primavera).

O talhão da região Sul apresentou os picos de diferencial mais intensos, porém foram menos abundantes que nas outras regiões (Figura 3c). Foram observados três picos, dois mais intensos (111 e 195 DAPA) e um mais discreto (231 DAPA). Esses picos corresponderam a novembro de 1998 (Primavera), janeiro de 1999 (Verão) e março de 1999 (Verão).

Optou-se também por analisar a diferencial secundária (D2) das curvas de progresso da CVC nos três talhões experimentais (Figura 4). Na região Noroeste os picos de D2 ocorreram aos 55, 126 e 218 DAPA (Figura 4a), correspondendo a setembro

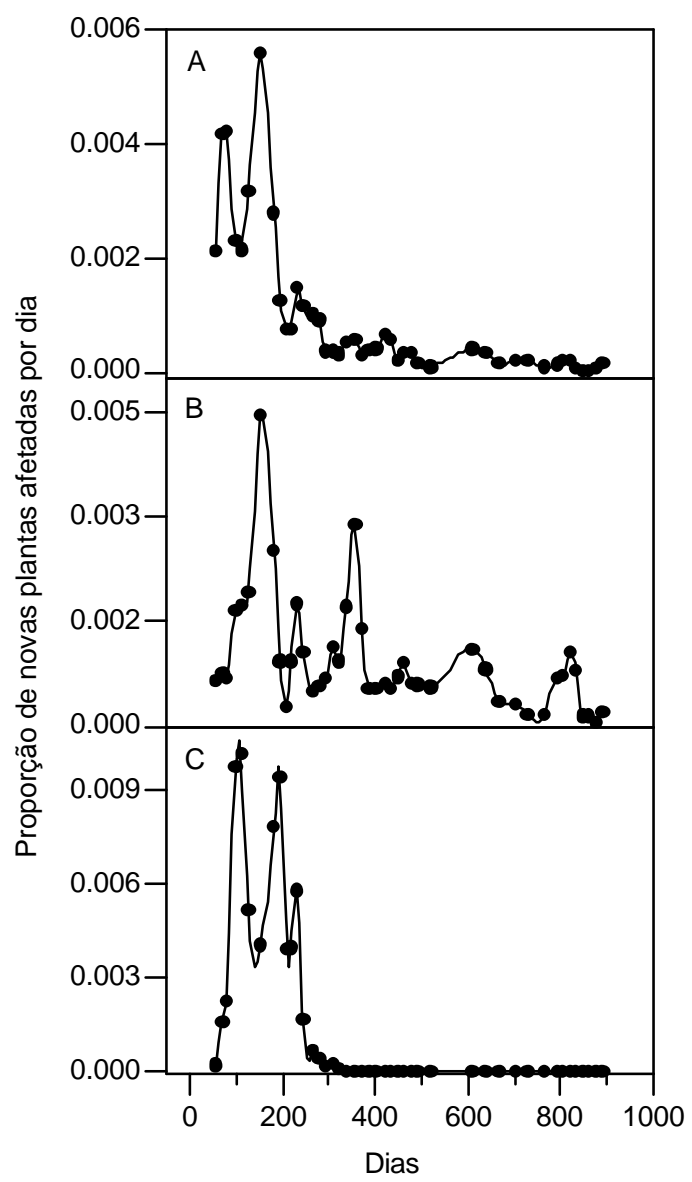

FIG. 3 - Diferenciais das curvas de progresso da Clorose Variegada dos Citros (CVC) originais dos talhões experimentais das regiões Noroeste (A), Centro (B) e Sul (C).

de 1998 (Inverno), novembro de 1998 (Primavera) e fevereiro de 1999 (Verão). Picos de menor intensidade ocorreram posteriormente, correspondendo aos menores picos da diferencial (Figura 4a). Na região Centro os picos de D2 ocorreram aos 126, 218 e 337 DAPA (Figura 4b), correspondendo a novembro de 1998 (Primavera), fevereiro de 1999 (Verão) e junho de 1999 (Outono). Picos de menor intensidade e mal definidos ocorreram ao longo da epidemia. Ao contrário das outras regiões, na região Sul foram detectados três picos de D2 (Figura 4c). Esses picos ocorreram aos 71, 181 e 218 DAPA, correspondendo a final de setembro de 1998 (início da Primavera), janeiro de 1999 (Verão) e fevereiro de 1999 (Verão).

Modelos consagrados apresentam um pico de derivada. Esse pico pode ocorrer no início da epidemia (Monomolecular), ao redor de $37 \%$ (Gompertz) ou 50\% de incidência (Logístico) (Campbell \& Madden, 1990; Bergamin Filho \& Amorim, 1996). Os modelos duplo-sigmóide, por outro lado, apresentam geralmente dois picos de derivada (Hau et al., 1993; Bergamin Filho \& Amorim, 1996; Laranjeira, 1997). A explicação matemática, não biológica - para o não-ajuste de modelos aos dados originais (não divididos em segmentos) das regiões Noroeste e Centro é a ocorrência, nesses talhões, de diversos picos de diferencial. 
Dinâmica temporal da clorose variegada dos citros em três regiões ...

Não importando a intensidade, foram observados cinco picos de diferencial em cada uma das áreas. Esses picos não ocorreram em anos diferentes - como seria de se esperar considerando-se os dados de Laranjeira (1997) - mas sim em "lotes" de dois a três por ano. Na região Sul, foram observados três picos; no entanto, como o terceiro foi de baixa intensidade, no ajuste matemático ficou confundido com o segundo, proporcionando um bom ajuste aos modelos duplo-sigmóides.

Traçando um paralelo com a física clássica, a curva de progresso de uma doença pode ser vista como o "espaço" percorrido em função do tempo. A diferencial é, então, a representação da velocidade em função do tempo e, a diferencial secundária, obtida por derivação da primária, pode ser considerada a aceleração em dado tempot. Assim, os picos de diferencial observados nada mais são que momentos em que a velocidade de progresso da doença aumentou. Em outras palavras, períodos em que aumentava a quantidade de aparecimento de novas plantas sintomáticas.

De maneira complementar, também foram deduzidas as diferenciais secundárias, representativas da aceleração. Ou seja, picos de diferencial secundária representam os momentos em que o aparecimento de novas plantas doentes teve seu impulso máximo. Da mesma forma que para as diferenciais primárias, os picos da secundária ocorreram via de regra em Primavera ou Verão, em especial os picos de maior intensidade.

Apesar das diferenças entre nossos dados e os apresentados por Laranjeira (1997), é notável como os picos de diferencial aqui registrados ocorreram, no mais das vezes, na Primavera ou no Verão, épocas também relatadas por aquele autor. De todos os picos observados, apenas dois ocorreram em Inverno e nenhum, em Outono. Também Palazzo \& Carvalho (1992) observaram que o progresso da CVC é mais acentuado entre a Primavera e o Verão, fato que supuseram estar relacionado a maiores temperatura e precipitação pluviométrica, fatores cruciais para um maior desenvolvimento de brotações. No entanto, aquelas autoras reportaram esse comportamento para proporção de folhas sintomáticas em ramos marcados.

A ocorrência de maior aceleração e velocidade do progresso da CVC em certas épocas é, certamente, fato relevante. No entanto, o simples exame desses acontecimentos não permite que se afirme que Primaveras e Verões são as épocas de maior infecção; afinal de contas, não se sabe ao certo qual o período de incubação da doença, não sendo, com certeza, restrito a poucos dias (Lopes et al., 1996; Laranjeira, 1997). Considerando também o que foi discutido para os ajustes dos segmentos de curvas, é lícito admitir apenas que a Primavera e o Verão são épocas de maior manifestação de sintomas. Como observado por Palazzo \& Carvalho (1992), é possível que isto esteja relacionado a fatores climáticos. Por outro lado, Pereira (2000), trabalhando com inoculação artificial de X. fastidiosa nas regiões Noroeste e Sul de São Paulo (mesmos talhões usados neste trabalho), obteve indicação de que um maior número de infecções bem sucedidas ocorriam em meses de Primavera e Verão, em comparação aos meses de Outono e Inverno. Corroborando essas informações, Martins et al. (2000), por meio de simulação, conseguiram ajustar um

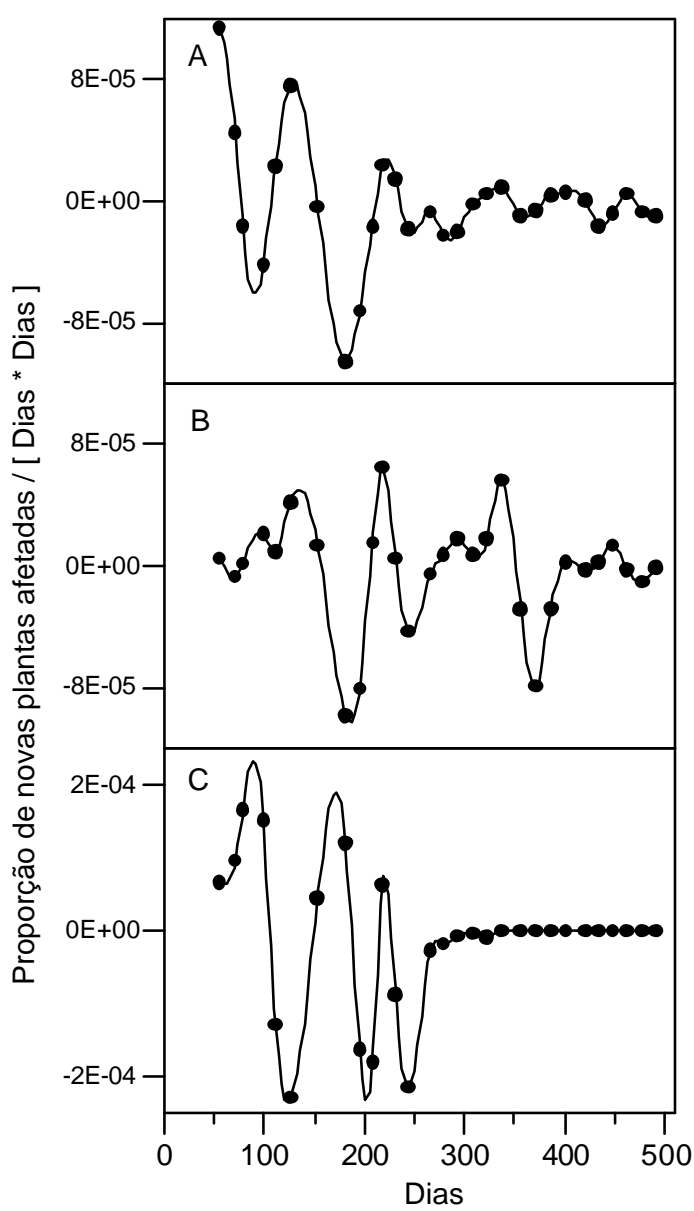

FIG. 4 - Diferenciais secundárias das curvas de progresso originais da Clorose Variegada dos Citros (CVC) dos talhões experimentais das regiões Noroeste (A), Centro (B) e Sul (C).

modelo aos dados colhidos por Laranjeira (1997). Esse modelo só obteve sucesso quando foi introduzida uma variável para o tipo de vôo das cigarrinhas e quando se considerou que os vetores só transmitiam a bactéria para plantas não-estressadas. Se isso de fato se verifica, pode-se inferir que as infecções ocorrem preferencialmente em meses de Primavera e Verão, assim como é nessa época que ocorrem as maiores taxas de aparecimento de sintomas. Em conseqüência, na prática, o período de incubação seria de cerca de 12 meses. A existência de vários picos de diferencial é coerente com a idéia de que os fluxos de brotação têm influência direta na infecção, mas não pode ser demonstrada pelos dados aqui obtidos. No entanto, essa influência não se relaciona simplesmente com sua quantidade, mas com sua qualidade, como abordado por Pereira (2000).

\section{AGRADECIMENTOS}

Os autores agradecem ao técnico Genésio S. da Silva (CCSM-IAC) a ajuda na coleta dos dados, ao Centro de Citricultura - IAC por ter permitido uso de sua estrutura e ao Fundecitrus e à FAPESP pelo auxílio financeiro para execução deste trabalho. 


\section{REFERÊNCIAS BIBLIOGRÁFICAS}

AYRES, A.J. Intensidade da clorose variegada dos citros em pomares comerciais de laranja do Estado de São Paulo e sul do Triângulo Mineiro. (Dissertação de Mestrado) FCAV/UNESP. Jaboticabal, 2000.

BERGAMIN FILHO, A. \& AMORIM, L. Doenças de Plantas Tropicais: Epidemiologia e Controle Econômico. São Paulo, Ceres. 1996.

CAMPBELL, C.L. \& MADDEN, L.V. Introduction to Plant Disease Epidemiology. New York, Wiley. 1990.

CHAN, M. \& JEGER, M.J. An analytical model of plant virus disease dynamics with roguing and replanting. Journal of Applied Ecology 31:413-427. 1994.

CHANG, C.J., GARNIER, M., ZREIK, L., ROSSETI, V. \& BOVÉ, J.M. Culture and serological detection of the xylem-limited bacterium causing citrus variegated chlorosis and its identification as a strain of Xylella fastidiosa. Current Microbiology 27:137-142. 1993.

FUNDECITRUS. Estatísticas CVC: incidência da CVC por região 2001. Disponível em: <http://www.fundecitrus.com.br/escvcbr.html> Acesso em: 12 jan. 2002.

GARCIA JUNIOR, A., LOPES, J.R.S. \& BERETTA, M.J.G. Population survey of leafhopper vectors of Xylella fastidiosa in citrus nurseries, in Brazil. Fruits 52:371-374. 1997.

GOTTWALD, T.R., GIDTTI, F.B., SANTOS, J.M. \& CARVALHO, A.C. Preliminary spatial and temporal analysis of citrus variegated chlorosis in Brazil. Proceedings of the 12th Conference of International Organization of Citrus Virologists Riverside, CA. 1993, pp.327-335.

HAU, B., AMORIM, L. \& BERGAMIN FILHO, A. Mathematical functions to describe disease progress curves of double sigmoid pattern. Phytopathology 83:928-932. 1993.

LARANJEIRA, F.F. Dinâmica Espacial e Temporal da Clorose Variegada dos Citros. (Dissertação de Mestrado) ESALQ/USP. Piracicaba, 1997.

LARANJEIRA, F.F. Epidemiologia da Clorose Variegada dos Citros em Três Regiões do Estado de São Paulo. (Tese de Doutorado) ESALQ/ USP. Piracicaba, 2002.

LARANJEIRA, F.F., POMPEU JUNIOR, J. \& PALAZZO, D. Sementes de frutos de laranja 'Natal' afetados pela clorose variegada dos citros: germinação, crescimento de plântulas e não-transmissão de Xylella fastidiosa. Laranja 21:161-173. 2000.
LOPES, J.R.S. Estudos com vetores de Xylella fastidiosa e implicações no manejo da clorose variegada dos citros. Laranja 20:329-344. 1999. LOPES, J.R.S., BERETTA, M.J.G., HARAKAVA, R., ALMEIDA, R.P.P., KRÜGNER, R. \& GARCIA Jr., A. Confirmação da transmissão por cigarrinhas do agente causal da Clorose Variegada dos Citros, Xylella fastidiosa. Fitopatologia Brasileira 2:343. 1996. (Resumo)

MARTINS, M.L., CEOTTO, G., ALVES, S.G., BUFON, C.C.B., SILVA, J.M. \& LARANJEIRA, F.F. A cellular automata model for citrus variegated chlorosis. Physical Review E 62:7024-7030. 2000.

NUNES, W.M.C. Epidemiologia da clorose variegada dos citros (CVC) avaliada por sintomas e diagnóstico serológico e molecular de Xylella fastidiosa. (Tese de Doutorado) FCA/UNESP.Botucatu, 1999.

PAIVA, P.E.B., SILVA, J.L. da, GRAVENA, S. \& YAMAMOTO, P.T. Cigarrinhas do xilema em pomares de laranja do Estado de São Paulo. Laranja 17:41-54. 1996.

PALAZZO, D.A. \& CARVALHO, M.L.V. Desenvolvimento e progresso da Clorose Variegada dos Citros (CVC) em pomares de Colina, SP. Laranja 13:489-502. 1992.

PARADELA FILHO, O., SUGIMORI, M.H., RIBEIRO, I.A., GARCIA JR., A., BERETTA, M.J.G., HARAKAWA, R., MACHADO, M.A., LARANJEIRA, F.F., RODRIGUES NETO, J. \& BERIAM, L.O.S. Constatação de Xylella fastidiosa em cafeeiro no Brasil. Summa Phytopathologica 23:46-49. 1997.

PEREIRA, E.F. Estudo de fatores sazonais relacionados a transmissão de Xylella fastidiosa em pomares de citros. (Dissertação de Mestrado) - ESALQ/USP. Piracicaba, 2000.

PREJUÍZOS com a CVC. Informativo CCSM. Setembro, 2001.

ROBERTO, S.R., COUTINHO, A., LIMA, J.E.O., MIRANDA, V.S. \& CARLOS, E.F. Transmissão de Xylella fastidiosa pelas cigarrinhas Dilobopterus costalimai, Acrogonia terminalis e Oncometopia facialis (Hemiptera: Cicadellidae) em citros. Fitopatologia Brasileira 21:517-518. 1996.

ROSSETI, V., GARNIER, M.,BOVÉ, J.M. BERETTA, M.J.G., TEIXEIRA, A.R., QUAGGIO, J.A. \& DE NEGRI, J.D. Présence de bactéries dans le xylème d'orangers atteints de chlorose variégée, une nouvelle maladie des agrumes au Brésil. Comptes Rendus Académie des Sciences de Paris, t.310, serie III, 1990. pp.345-349.

WENDLAND, A. Diversidade genética de Xylella fastidiosa em três regiões produtoras de citros (Citrus sinensis) do Estado de Sao Paulo. (Dissertação de Mestrado) - ESALQ/USP. Piracicaba, 2000. 